\title{
Analysis of the basic components and free amino acid composition of pineapple fruit vinegar
}

\author{
Xiao-fang Wang ${ }^{1,2}$, Yuhao $\mathrm{Hu}^{1,2}$, Ji-Hua Li ${ }^{1,2, *}$, Li Zhang ${ }^{1,2}$, Xiao Gong ${ }^{1,2}$ and Hui Huang ${ }^{1,2}$ \\ ${ }^{1}$ Key Laboratory of Tropical Crop Products Processing of Ministry of Agriculture and Rural Affairs, Agricultural Products Processing \\ Research Institute, Chinese Academy of Tropical Agricultural Sciences, Zhanjiang 524001, Guangdong, China; \\ ${ }^{2}$ Hainan Key Laboratory of Storage \& Processing of Fruits and Vegetables, Zhanjiang 524001, Guangdong, China
}

\begin{abstract}
Acetic acid fermentation is an essential step in producing high-quality vinegar. In this study, the alcoholic medium was used as a seed broth for acetic fermentation using Acetobacter aceti as the inoculum for approximately 7 days at $32^{\circ} \mathrm{C}$ to obtain $45.87 \mathrm{~g} / \mathrm{L}$ acetic acid. During the Acetic acid fermentation stage, the content of the total polyphenols decreased first and then increased. Based on amino acid analyzer analysis, pineapple vinegar contains 18 kinds of free amino acids. And the contents of sweet and umami free amino acids are the main free amino acids, followed by bitter amino acids.
\end{abstract}

\section{Introduction}

Pineapple (Ananas comosus (L.) Merr.), which originated in the north of the Amazon river and it was distributed in America, Europe, Africa, and Asia and the south of China $^{[1]}$. Pineapple pulp is rich in water, sugar and compounds with special health benefits (manganese, vitamins, bromelain), which makes them suitable for fermentation ${ }^{[2]}$. However, the fruit juice, fresh eating and canned pineapple are the main consumption forms. Fruit vinegar is an alternative to provide new opportunity for pineapple consumption. Meanwhile, the nutrition and flavor have changed greatly during the fermentation of pineapple vinegar, the free amino acids are considered to be an important contributor to the distinctive taste of vinegar $^{[3]}$. There are few studies on bioactive compounds of Pineapple Vinegar, indicating that fermentation can promote the production of new functional components ${ }^{[4]}$. Against this background, the main objectives of the present study were to investigate the basic components and amino acid composition in pineapple fruit vinegar.

\section{Materials and Methods}

\subsection{Chemicals and reagents}

Pineapple fruits were purchased from the local market. $S$. cerevisiae (dry yeast) was purchased from Angel Yeast Co., Ltd (Yichang, China). A. pasteurianus AS1.41 were obtained from Agricultural Product Processing Research Institute, Chinese Academy of Tropical Agricultural Sciences.

\subsection{Vinegar making}

The Pineapple pulp (TSS content, $16^{\circ} \mathrm{Brix} ; \mathrm{pH}$ and acid value, nature value) was fermented with yeast at $28^{\circ} \mathrm{C}$ for three days to obtain pineapple wine. The wine was the secondary fermented by adding to acetobacter AS1.41 $\left(\mathrm{OD}_{600}=0.8\right)$ at $4 \%$, on a rotary shaker incubator $(180 \mathrm{rpm})$ for $7 \mathrm{~d}$ at $30^{\circ} \mathrm{C}$. The fermentation was finished when the acetic acid content remained stable.

\subsection{Determination of the $\mathrm{pH}$, soluble solids, ethanol, acid value, and cell growth}

The $\mathrm{pH}$ was measured using a PHS-3E $\mathrm{pH}$ meter (TecFront Electronics Co. Ltd., Shanghai, China). Titratable acidity (TA) was detected by titrating with 0.01 $\mathrm{M} \mathrm{NaOH}$ and expressed as g acetic acid ${ }^{[5]}$. TSS ( ${ }^{\circ} \mathrm{Brix}$ ) of the vinegar samples was analyzed using RA-250WE refractometer (KEM, Kyoto, Japan). Ethanol content (\%) was determined by the pycnometer.

\subsection{Determination of the total phenolics in pineapple vinegar}

The total soluble phenolic content of the samples was determined by a Folin-Ciocalteau's reagent, with gallic acid as a standard ${ }^{[6]}$. In each case, $0.5 \mathrm{~mL}$ of the diluted sample was mixed with $5 \mathrm{~mL}$ Folin-Ciocalteu's phenol reagent incubated at room temperature for $3 \mathrm{~min}$. Subsequently, $2 \mathrm{~mL}$ of $150 \mathrm{~g} / \mathrm{L} \mathrm{Na}_{2} \mathrm{CO}_{3}$ solution was added, and the resulting mixture was diluted with distilled water to $10 \mathrm{~mL}$ before being left to stand for $50 \mathrm{~min}$ at room temperature. The absorbance was measured at 760 $\mathrm{nm}$. The total phenolics were calculated as gallic acid equiva-lents (GAE) from the calibration curve (obtained

\footnotetext{
* Corresponding author: foodpaper@126.com
} 
from the gallic acid standard solution and expressed as $\mathrm{mg}$ $\mathrm{GAE} / \mathrm{g})$.

\subsection{Determination of the free amino acids}

In order to determine the free amino acid composition of pineapple pineapple vinegar, A300 amino acid analyzer (membra Pure GmbH, Germany) was used with some modifications $^{[7]}$. In each case, pineapple vinegar samples $(4 \mathrm{ml})$ were precipitated by adding $1 \mathrm{ml}$ of $10 \%(\mathrm{w} / \mathrm{v})$ sulfosalicylic acid solution, then the mixture was incubated at $4^{\circ} \mathrm{C}$ for $1 \mathrm{~h}$, then centrifuged $\left(4^{\circ} \mathrm{C}, 15 \mathrm{~min}\right)$ $(8000 \times \mathrm{g})$. The supernatant was then passed through a $0.45 \mathrm{~mm}$ membrane (Ameritch scientific Co, LTD.,Tianjin, China). Ammonium was removed from the eluent using a precolumn (vs213, membrane pure). Amino acids were separated by liquid chromatography on separation column TS263 (membrane pure). Ninhydrin reaction showed that the absorbance was determined at $570 \mathrm{~nm}$, except proline, at $440 \mathrm{~nm}$. The calibration curve of pure standard was used to quantify the concentration of each amino acid and expressed as $\mathrm{mg} / \mathrm{L}$.

\section{3 result and discussion}

\subsection{Quality parameters during vinegar brewing}

Table 1. The main wine and vinegar parameters.

\begin{tabular}{|l|l|l|}
\hline & wine & vinegar \\
\hline Volume (L) & $0.80 \pm 0.13$ & $0.70 \pm 0.12$ \\
\hline TSS ( ${ }^{\circ}$ Brix) & $4.12 \pm 0.10$ & $1.12 \pm 0.13$ \\
\hline pH value & $4.57 \pm 0.12$ & $2.97 \pm 0.23$ \\
\hline Alcohol (\%vol) & $8.12 \pm 0.45$ & $\mathrm{NF}$ \\
\hline TA (g/kg) & $1.33 \pm 0.24$ & $45.87 \pm 0.15$ \\
\hline Fermentation time (d) & $3 \mathrm{~d}$ & $7 \mathrm{~d}$ \\
\hline
\end{tabular}

The fermentation process of the pineapple wine was carried out at $32^{\circ} \mathrm{C}$ for 7 days to produce vinegar that was characterized as shown in Table 1. During fermentation, $\mathrm{pH}$ value decreased to the lowest value $(2.97 \pm 0.01)$. The $\mathrm{pH}$ tended to be constant value when further prolonged the brewing time. Correspondingly, the highest TA value formation was displayed on day 7 , reaching concentration of $45.87 \mathrm{~g} / \mathrm{kg}$, and then it's stable. There were slowly decrease in TSS ( ${ }^{\circ}$ Brix) and during the vinegar brewing stage, ranging from 4.12 to 1.12 .

\subsection{Effects of pineapple vinegar-making on total phenolic content}

The pineapple is naturally rich in polyphenols, which are powerful antioxidants. The effects of the vinegar brewing on the total polyphenol content (TPC) of pineapple vinegar are presented in Fig. 1. The total polyphenol content in the sample showed a downward trend during the early stage of fermentation, which may due to the hydrolysis and oxidation of native polyphenols ${ }^{[8]}$. With the further fermentation, the acetic acid bacteria would secrete a large number of enzymes, such as various glycoside hydrolases, which can effectively hydrolyze the glucose combined with polyphenols and release phenolic hydroxyl groups. Thus, the content of polyphenols presented a increased tendency, but the increasing trend was very weak. The highest TPC formation was displayed on day 7 , reaching concentration of $1.75 \mathrm{mg} \mathrm{GAE} / \mathrm{mL}$.

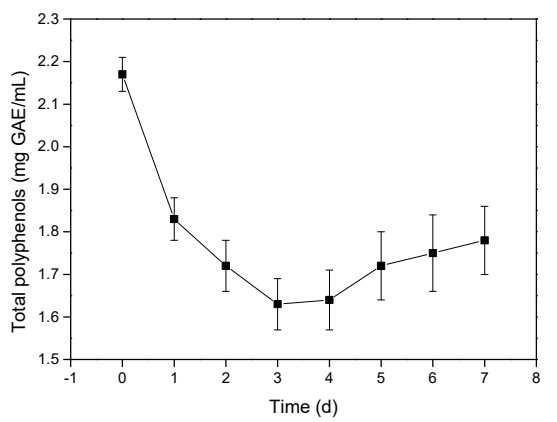

Fig. 1. Changes of total polyphenols content during Acetic Acid fermentation

\subsection{Effects of pineapple vinegar-making on the free amino acids}

In general, amino acids not only affect the taste of fruit vinegar, but also are important nutrients ${ }^{[9]}$. The taste of vinegar was generally considered to be dominated by sour, followed by sweet and umami taste and slight salty and bitterness, which may be a result of the interaction and balance among the different taste components. The free amino acids are considered to be an important contributor to the distinctive taste of vinegar. As shown in Table 2, the contents of 18 free amino acids in pineapple vinegar were investigated. According to the taste characteristics, the free amino acids were classified as umami, sweet, bitter, and tasteless. The content of sweet amino acids was the highest, reaching the concentration of $380.5 \mathrm{mg} / \mathrm{L}$, followed by the umami and bitter amino acids. The total essential free amino acids, which is good for human health, reached $275.1 \pm 2.84 \mathrm{mg} / \mathrm{L}$. The total amino acid content is three times that of essential amino acids.

Table 2. The main wine and vinegar parameters.

\begin{tabular}{|l|l|l|}
\hline $\begin{array}{c}\text { Free amino } \\
\text { acid }\end{array}$ & $\begin{array}{c}\text { Taste } \\
\text { attributes }\end{array}$ & $\begin{array}{c}\text { Concentration } \\
(\mathbf{m g} / \mathbf{L} \text { ) }\end{array}$ \\
\hline Asp & umami & $37.13 \pm 0.17$ \\
\hline Glu & umami & $23.12 \pm 0.24$ \\
\hline \multicolumn{2}{|c|}{ Total umami } & $60.25 \pm 0.31$ \\
\hline Gly & Sweet & $53.15 \pm 0.37$ \\
\hline Ala & Sweet & $103.7 \pm 0.42$ \\
\hline Thr* & Sweet & $40.03 \pm 0.12$ \\
\hline Ser & Sweet & $20.15 \pm 0.35$ \\
\hline Pro & Sweet & $97.27 \pm 0.47$ \\
\hline \multicolumn{2}{|c|}{ Total sweet } & $314.3 \pm 1.73$ \\
\hline Met* & bitter & $12.13 \pm 0.07$ \\
\hline Ile* & bitter & $12.03 \pm 0.27$ \\
\hline Leu* & bitter & $20.15 \pm 0.18$ \\
\hline Phe* & bitter & $25.27 \pm 0.13$ \\
\hline Lys* & bitter & $36.15 \pm 0.25$ \\
\hline His* & bitter & $10.05 \pm 0.72$ \\
\hline Arg* & bitter & $46.07 \pm 0.13$ \\
\hline
\end{tabular}




\begin{tabular}{|l|l|l|}
\hline Trp* & bitter & $6.004 \pm 0.27$ \\
\hline Tyr & bitter & $40.02 \pm 0.35$ \\
\hline Val $^{\mid 2}$ bitter & $27.21 \pm 0.18$ \\
\hline \multicolumn{2}{|c|}{ Total bitter } & $235.1 \pm 2.55$ \\
\hline Cys Tasteless & $15.05 \pm 0.25$ \\
\hline $\begin{array}{c}\text { Total essential free amino } \\
\text { acids }\end{array}$ & $275.1 \pm 2.84$ \\
\hline $\begin{array}{c}\text { Content of total free amino } \\
\text { acids }\end{array}$ & $624.7 \pm 4.84$ \\
\hline
\end{tabular}

\section{Conclusion}

In this study, we investigated the basic components and free amino acids composition in the pineapple fruit vinegar. The various components have changed greatly during the process of vinegar-making. The highest TA value formation was displayed on day 7 , reaching concentration of $45.87 \mathrm{~g} / \mathrm{kg}$. The total polyphenol content in the sample showed a downward trend during the early stage of fermentation, and then presented a increased tendency. The free amino acids are considered to be an important contributor to the distinctive taste of vinegar. The content of sweet amino acids was the highest, reaching the concentration of $380.5 \mathrm{mg} / \mathrm{L}$, followed by the umami and bitter amino acids.

\section{Acknowledgments}

This research was funded by the Natural Science Foundation for Hainan Province of China (No. 219QN293), the Central Public-interest Scientific Institution Basal Research Fund for Chinese Academy of Tropical Agricultural Sciences (grant number 1630122017013), and the Modern Agriculture Industry Technology System Innovation Team Project of Guangdong Province of China (grant number 2019KJ117).

\section{References}

1. Bartholomew, D.P., Paull, R.E., Rohrbach, K.G. (Eds.). The Pineapple: Botany, Production and Uses. CAB International (2003).

2. O'Connor-Shaw, R.E., Roberts, R., Ford, A.L., Nottingham, S.M. Shelf life of minimally processed honeydew, kiwifruit, papaya, pineapple and cantaloupe. J. Food Sci. 59, 1202-1206 (1994).

3. Zhang, J. L., Huang, M. Q., \& Sun, G. B. Study on free amino acid composition of 4 famous vinegars in China. Journal of Food Safety and Quality, 5 (10), 312 4-3131 (2014).

4. Dellacassa, E. , Trenchs, O. , Laura Fariña, Debernardis, F. , \& Carrau, F. Pineapple (ananas comosus L. merr.) wine production in angola: characterisation of volatile aroma compounds and yeast native flora. International Journal of Food Microbiology, 241 (2017).

5. Lan, Y., Wu, J., Wang, X., Sun, X., Hackman, R. M., Li, Z., \& Feng, X. Evaluation of antioxidant capacity and flavor profile change of pomegranate wine during fermentation and aging process. Food Chemistry, 232, 777-787 (2017).

6. Quettier-Deleu, C., Gressier, B., Vasseur, J., Dine, T., Brunet, C., Luyckx, M., et al. Phenolic compounds and antioxidant activities of buckwheat (Fag-opyrum esculentum Moench) hulls and flour. Journal of Ethnopharmacology, 72(1), 35-42 (2000).

7. Schreckinger, M . E., Wang, J., Yousef, G., Lila, M. A ., \& Gonzalez de Mejia, E. Antioxidant capacity and in vitro inhibition of adipogenesis and in flammation by phenolic extracts of Vaccinium fl- oribundum and Aristotelia chilensis. Journal of A gricultural and Food Chemistry, 58(16), 8966-8976 (2010).

8. Czyzowska, A., \& Pogorzelski, E. Changes to polyphenols in the process of production of must and wines from blackcurrants and cherries. Part I. Total polyphenols and phenolic acids. European Food Research and Technology, 214 (2),148-154 (2002).

9. Xu, Ning, Chen, Yang, Huang, \& Yao et al. Effects of mixed cultures of saccharomyces cerevisiae and lactobacillus plantarum in alcoholic fermentation on the physicochemical and sensory properties of citrus vinegar. LWT-Food Science \& Technology, 84, 753763(2017). 